\title{
A Needs Assessment of Barriers to Cervical Cancer Screening in Vietnamese American Health Care Providers
}

\author{
Harry T. Kwon ${ }^{1}$, Felicia M. Solomon ${ }^{1}$, and Si Nguyen ${ }^{2}$ \\ ${ }^{1}$ Office of Education and Special Initiatives, National Cancer Institute \\ ${ }^{2}$ Vietnamese American Medical Association
}

\begin{abstract}
Vietnamese women living in the United States have a cervical cancer incidence rate that is five times that of White women. The low rate of cervical cancer screening among this high-risk population contributes to this disparity. In 2004, the National Cancer Institute collaborated with the Vietnamese American Medical Association to conduct a short needs assessment questionnaire (Pap Test Barriers Questionnaire for Health Care Providers) among its members to assess provider views about cervical cancer, barriers to Pap testing among Vietnamese women living in the United States, and types of patient education materials needed to help motivate Vietnamese women to receive a Pap test. Information from the questionnaire was used to inform development of a brochure and identify additional strategies to enhance outreach to Vietnamese women and providers. Almost all of the respondents (95\%) thought that Pap tests were "very important" in the early detection of cervical cancer in Vietnamese women. In addition, knowledge about the importance of Pap tests was identified as the most influential factor for Vietnamese women not seeking a Pap test. Print materials that included both English and Vietnamese translations in the same publication were cited as a preferred communication tool. Further, health education through Vietnamese media was recommended as a primary strategy for reaching women with educational messages. Findings from this needs assessment contributes to a larger formative research effort to build NCI's cervical cancer education program within its Office of Education and Special Initiatives.
\end{abstract}

(c) 2006 Californian Journal of Health Promotion. All rights reserved.

Keywords: Vietnamese women, cervical cancer, Pap test, health care providers

\section{Introduction}

The introduction of the Pap test as an effective screening tool has contributed to significant reductions in morbidity and mortality due to cervical cancer (National Institutes of Health, 1996). Despite these advances, some groups of women, including Vietnamese women living in the United States, continue to suffer disproportionately from this preventable disease. According to data from the Surveillance, Epidemiology, and End Results (SEER) Program, Vietnamese women have the highest incidence of cervical cancer, a rate estimated to be five times that of White women. Further, cervical cancer is the most common cancer among Vietnamese women (National Cancer Institute, 1996).
Cervical cancer screening rates in Vietnamese women are lower compared with other ethnic/minority groups. Since the late 1990s, studies conducted in areas with large Vietnamese populations, including California, Houston, Texas, and Seattle, Washington, estimate cervical cancer screening rates ranging from 43 to 74 percent for ever having and recent receipt of a Pap test (Chilton, Gor, Hajek, \& Jones, 2005; De Alba, Ngo-Metzger, Sweningson, \& Hubbell, 2005; Lai, Nguyen, Mock, McPhee, Doan, \& Pham, 2004; McPhee, Stewart, Brock, Bird, Jenkins, \& Pham, 1997a; Nguyen, McPhee, Gildengorin, Nguyen, Wong, Lai et al., 2006; Taylor, Schwartz, Yasui, Burke, Shu, Lam et al., 2004(a); Taylor, Yasui, Burke, Nguyen, Acorda, Thai et al., 2004b). Data from the 2000 National Health Interview Survey reported age-adjusted screening rates of about 
71 percent among Vietnamese women compared with about 78 percent in Hispanics, 84 percent in Blacks, and 83 percent in Whites (Swan, Breen, Coates, Rimer, \& Lee, 2003). These lower levels of screening can result in later stage cancer diagnosis.

\section{Barriers to Cervical Cancer Screening}

Physician factors and barriers to screening are consistently reported in the literature. In a Seattle-based study, investigators surveyed 518 Vietnamese women aged 18-64 to assess screening behavior, personal physician factors (among women with a regular physician), and health care barriers, among other factors. In an analysis of a subset of 412 women who reported having a regular doctor, only 68 percent reported being screened within the last two years. The following physician characteristics were associated with lack of recent screening: having a male physician, receiving care at a private physician office, and lack of physician recommendation. The authors suggest that patients' unwillingness to seek gynecologic services from a male provider and/or an increased commitment to screening among female physicians may explain the association between having a male provider and decreased screening. They attribute decreased screening in private physician offices to the lack of preventive care reminders in private settings and the greater ease of referring female patients to female providers in a clinic-based system compared with the private setting (Taylor et al., 2004a; Taylor et al., 2004b). In a qualitative study of 645 Vietnamese women in San Francisco and Sacramento, having a Vietnamese physician was a barrier to receiving a Pap test (McPhee, Bird, Davis, Ha, Jenkins, \& Le, 1997b). These barriers may be due to the lack of Pap test training among Vietnamese American physicians trained in Vietnam, emphasis on acute versus preventive care, physician sensitivity to the modesty of female patients, and female patients' reluctance to receive gynecologic care from a male physician (McPhee et al., 1997b). Underscoring the impact of physician barriers, Nguyen and colleagues' intervention to increase Vietnamese physician knowledge of Pap test screening contributed to an almost seven percent increase in screening among the intervention communities compared with a three-percent decline in the control communities. More women in the intervention communities reported having their physician offer a Pap test. Those with a female Vietnamese physician or non Vietnamese male physician and those who reported that they were treated with respect by their physician were also more likely to report receipt of a Pap test (Nguyen et al., 2006).

Physician beliefs and medical training have been shown to contribute to low rates of Pap testing among Vietnamese women. A majority of physicians questioned in one study incorrectly believed that the risk of cervical cancer among Vietnamese women was relatively low. Vietnamese physicians who believed that Vietnamese women were at the same or higher risk than the general population performed more Pap tests than those who believed that the risk was the same or lower (Hyman, Cameron, Singh, \& Stewart, 2003). Three studies indicated that women who had a Vietnamese physician were less likely to have heard of the Pap test (McPhee et al., 1997b; Nguyen, McPhee, Nguyen, Lam, \& Mock, 2002; Yi, 1994). One explanation for this may be that these physicians lack training in preventive care (Lai et al., 2004; McPhee et al., 1997b; Yi, 1994). Another possibility is that Vietnamese physicians may assume that unmarried women are not sexually active and therefore do not offer them a Pap test (Nguyen et al., 2002).

The important role of the Vietnamese physician in increasing routine Pap screening cannot be underestimated. The majority of Vietnamese women are served by Vietnamese physicians (McPhee, 2002), and the literature documents the effect that these physicians' recommendation can have on receipt of screening (Nguyen et al., 2006a; Taylor et al., 2004b). As such, increasing Vietnamese physicians' awareness and commitment to screening might potentially have a large impact on screening rates and subsequent cervical cancer incidence and mortality. Realizing this fact, the National Cancer Institute (NCI) collaborated closely with the Vietnamese American Medical Association (VAMA) while revising their Vietnamese and English-language 
booklet on the importance of Pap test screening. In 2004, the NCI collaborated with VAMA to conduct a short needs assessment questionnaire among its members. Information from the questionnaire was used to inform the development of the brochure, "Cervical Cancer: What Vietnamese Women Should Know," and identify additional strategies from the perspective of the provider to enhance outreach to Vietnamese women and health care providers. This formative work was not intended as a research study, but instead as part of larger formative research efforts to inform and guide NCI's cervical cancer education program within its Office of Education and Special Initiatives.

\section{Methods}

NCI's Office of Education and Special Initiatives and VAMA collaboratively developed the Pap Test Barriers Questionnaire for Health Care Providers. The Vietnamese American Medical Association is a non-profit organization representing over 1,000 physicians of Vietnamese descent in America. VAMA is also affiliated with about 13 local chapters of Vietnamese American health professional associations in different states, such as California and Texas. Created in 1990, VAMA is dedicated to the advancement of healthcare, health education and charity work in our Vietnamese American community.

The purpose of the questionnaire was to collect information on provider perceived barriers to cervical cancer screening for Vietnamese women living in the United States and provide recommendations for enhancing outreach to Vietnamese women and physicians. Questionnaire responses helped to guide revision of the current brochure and enhance outreach efforts around cervical cancer screening in Vietnamese women living in the United States.

The questionnaire contained 20 items, consisting of both open and closed ended questions. Items addressed provider-perceived cervical cancer screening barriers among Vietnamese women in the United States, preferences for patient education materials, and provider characteristics. A sample of questions included: "In your opinion, are there any reasons why Vietnamese providers may not recommend Pap tests for specific Vietnamese patients?”; “In your opinion, what should be done to encourage more Vietnamese women to get Pap tests?”; and "What types of patient education materials are needed to help motivate Vietnamese women who have rarely or never received a Pap test?” The survey also included items related to the previous version of the brochure; however, these data are not reported in this manuscript. Completion time was estimated at approximately ten minutes.

The questionnaire was mailed to all members on the current VAMA mailing list along with a cover letter, co-signed by NCI and VAMA representatives and a postage-paid return envelope. Respondents had 30 days to complete and return the questionnaire. Prior to mailing the questionnaire, VAMA featured a short announcement about the questionnaire in its quarterly newsletter to alert members that the questionnaire would be arriving via mail and to increase participation.

All data were entered into a database and analyzed using the Statistical Package for the Social Sciences (SPSS), version 12.0. Descriptive statistics (frequencies and percentages) were computed to summarize the data. Open ended responses were recorded, analyzed, and grouped into thematic categories. The questionnaire received Office of Management and Budget approval.

\section{Results}

\section{Response Rate}

A total of 1,162 questionnaires with postagepaid return envelopes were mailed to VAMA members nationwide. A low response rate led to extending the data collection period beyond the deadline. After about two months, 142 questionnaires were completed and returned. Another 58 questionnaires were labeled as undeliverable and returned by the U.S. Postal Service. Excluding questionnaires returned undeliverable, the response rate was approximately 13 percent. 


\section{Sample Characteristics}

Sample characteristics varied by type of health care provider, work setting, and location of medical training. However, most providers were family practitioners, medically trained in the United States, and in private practice. Table 1 provides a summary of the sample characteristics.

Table 1

Summary of selected sample characteristics

\begin{tabular}{|c|c|c|}
\hline Characteristic & Frequency & Percentage \\
\hline \multicolumn{3}{|l|}{ Provider Category* } \\
\hline Family practitioner & 73 & 52.5 \\
\hline Internal medicine & 23 & 16.5 \\
\hline OB/GYN & 8 & 5.8 \\
\hline Other & 35 & 25.2 \\
\hline Patients Mostly Female^ & 46 & 35.7 \\
\hline \multicolumn{3}{|l|}{ Pap Test Training Received ${ }^{+}$} \\
\hline United States & 75 & 53.2 \\
\hline Vietnam & 13 & 9.2 \\
\hline Both U.S. and Vietnam & 32 & 22.7 \\
\hline Other & 4 & 2.8 \\
\hline Not trained for Pap testing & 17 & 12.1 \\
\hline \multicolumn{3}{|l|}{ Practice Settings $^{+}$} \\
\hline Private practice & 90 & 63.8 \\
\hline Hospital or medical center & 17 & 12.1 \\
\hline Clinic or medical center & 13 & 9.2 \\
\hline HMO & 3 & 2.1 \\
\hline Other & 18 & 12.8 \\
\hline
\end{tabular}

\section{Cervical Cancer and Pap Tests}

Respondents were asked several questions about the importance of Pap tests, the level of influence specific factors have on Vietnamese women receiving Pap tests, reasons why Vietnamese providers may not recommend Pap tests, and what should be done to encourage more Vietnamese women to receive Pap tests. Almost all respondents (133 respondents or 95\%) reported that routine Pap tests were "very important" in the early detection of cervical cancer in Vietnamese women living in the United States, and the remainder indicated that it was "somewhat important."

When asked the level of influence of specific factors to receipt of screening, on a scale of 1 (very influential) to 5 (not very influential), about 58 percent indicated that a lack of knowledge about the importance of Pap tests was "very influential" in explaining why Vietnamese women may not seek a Pap test. Many also reported that lack of access to screening services (51.8\%), language barriers (49.3\%), and fear about cancer (45.3\%) were "somewhat" to "very influential." More than 25 percent of the respondents selected the high cost of a Pap test as "not very influential.” Responses about the influence of cultural or religious beliefs were mixed. Table 2 summarizes these data. Additional factors reported included modesty of women, lack of knowledge about cervical cancer, lack of a female provider, lack of understanding of Pap tests, fear of pain, and reluctance to get a Pap test. 
Table 2

Level of influence (reported as percentage) of each factor contributing to why Vietnamese women may not seek a Pap test $(\mathrm{N}=142)$

\begin{tabular}{|l|c|c|c|c|c|c|}
\hline \multicolumn{1}{|c|}{ Factor } & $\begin{array}{c}\text { Very } \\
\text { Influential }\end{array}$ & $\begin{array}{c}\text { Somewhat } \\
\text { Influential }\end{array}$ & Neutral & $\begin{array}{c}\text { Somewhat } \\
\text { Not } \\
\text { Influential }\end{array}$ & $\begin{array}{c}\text { Not Very } \\
\text { Influential }\end{array}$ & $\begin{array}{c}\text { Don't } \\
\text { Know }\end{array}$ \\
\hline $\begin{array}{c}\text { Lack of knowledge about } \\
\text { the importance of Pap } \\
\text { tests }\end{array}$ & 58.2 & 12.8 & 9.2 & 4.3 & 14.9 & 0.7 \\
\hline $\begin{array}{l}\text { No access to screening } \\
\text { services }\end{array}$ & 24.1 & 27.7 & 29.9 & 9.5 & 8.8 & -- \\
\hline Language barriers & 22.5 & 26.8 & 26.1 & 8.0 & 15.9 & 0.7 \\
\hline Fear about cancer & 23.4 & 21.9 & 27.0 & 12.4 & 13.9 & 1.5 \\
\hline Cost of Pap test is too high & 13.1 & 10.9 & 27.0 & 15.3 & 25.5 & 8.0 \\
\hline $\begin{array}{c}\text { Cultural or religious } \\
\text { beliefs }\end{array}$ & 21.5 & 24.4 & 16.3 & 9.6 & 23.0 & 5.2 \\
\hline
\end{tabular}

Ninety-nine respondents (69.7\%) provided their opinions about why Vietnamese providers may not recommend Pap tests to Vietnamese female patients. Some respondents provided little insight, reporting either that they did not know or that they personally always recommend Pap tests to their female patients. Open-ended responses were grouped into categories based on the most salient themes including health care provider, culture, and system barriers. Respondents also provided insight on why Vietnamese women do not adhere to provider recommendations to get a Pap test.

\section{Health Care Provider}

Health care provider issues emerged as an important theme. Respondents indicated that Vietnamese physicians may not recognize the importance of Pap tests as a screening tool for cervical cancer. One respondent indicated that physicians may not know that Vietnamese women are at high risk for cervical cancer. Some respondents indicated that male providers are not comfortable conducting a Pap test. Further, many respondents reported that some providers may not offer Pap tests to women and may be reluctant to explain the need for a Pap test. Some respondents indicated that fear of losing patients to other providers was a reason why they may not recommend Pap tests. Many respondents indicated that some Vietnamese providers may lack adequate training to administer Pap tests.
Several respondents also identified breakdowns in patient-provider communication as barrier to screening. Some respondents indicated that male providers may be reluctant to communicate about Pap tests and cervical cancer. Others felt uncomfortable explaining the procedure to older women and did not know the Vietnamese words to explain cervical cancer screening concepts to Vietnamese-speaking patients. One respondent felt that some providers may not be able to translate well enough to convince or educate women to undergo screening. Another commented that doctors present options and advice but do not push hard enough to convey the message of screening, therefore creating a gap between understanding the need for a Pap test and aiding in the decision making process of patients.

Culture. Among the cultural barriers providers cited as important were modesty, fear of compromising virginity, and reluctance to communicate about sexual behavior. One respondent indicated that "everything related to sex including sex organs is considered a taboo" and therefore if a female patient did not inquire about cervical cancer screening, the doctor would not discuss it. In addition, it was suggested that Vietnamese women are more embarrassed than women from other cultures about discussing female issues with male doctors. Other respondents indicated that 
Vietnamese women wanted to maintain their virginity (Vietnamese women thought that having a Pap test might result in loss of virginity). Another respondent suggested that "many women are not sexually active until they get married and therefore preferred to keep their virginity and hymen intact." Further, one respondent added that Vietnamese providers may not recommend Pap tests if the woman is unmarried.

System Barriers. Several respondents blamed systems-related barriers for the lack of screening recommendations. Many respondents indicated that providers have no time to recommend the Pap test and explain its benefits to their patients. Several respondents said that there is a financial burden on the patient to get a Pap test, especially for the uninsured that can influence receipt of a Pap test. Several respondents also cited issues related to lack of reimbursement from insurance companies to provide Pap tests and providers who simply do not conduct Pap tests.

\section{Refusal to Follow Provider Recommendations}

Respondents offered several reasons women may not get Pap tests even after a provider recommendation. Many respondents indicated that patients were "too busy" to get a Pap test. Other reasons included lack of education about the benefits of the Pap test, some women just "don't believe in it," and women often avoid the topic of Pap tests due to modesty. Others replied that Vietnamese women do not ask about the exam and they do not like male providers to conduct the Pap test, preferring a female provider, which is not always an option. Further, fear of the Pap test is a factor in patients refusing to get the screening. Respondents also reported that age is a factor, as their older Vietnamese women patients were reluctant to get the screening test.

Recommendations for Increasing
Screening
$\begin{aligned} & \text { Respondents suggested } \\ & \text { approaches to increase }\end{aligned}$ screening among

Vietnamese women: increase the awareness of the cervical cancer burden among Vietnamese women and the availability of Pap tests as a screening tool to the Vietnamese community and physicians, educate women on the importance of Pap test, and conduct active outreach to educate about Pap tests. Respondents suggested offering low- or no-cost Pap tests, more convenient appointments for Pap tests, translators, and female providers in order to reduce some of the system barriers that women may experience. The respondents recommended that health communication through television, radio, and newspaper channels be used to promote the benefits of screening. In general, a majority of the respondents felt that providing more education about Pap tests was a primary need and that providers needed to spend more time explaining the importance of the Pap test.

Types of Patient Education Materials Preferred by Providers

Respondents were asked what types of patient education materials are needed to help motivate Vietnamese women who have rarely or never received a Pap test. From a variety of types of patient education materials, most $(114,80.3 \%)$ selected "print materials that include both English and Vietnamese translations in the same publication.” A "one-page fact sheet with basic, introductory information" had the second highest number of selections - 106 respondents (74.6\%). "Poster with motivational message" and "printed booklet with detailed information" had the least number of selections - 81 respondents (57\%) and 77 respondents (54.2\%), respectively. Figure 1 displays the distribution of responses on the selected types of patient education materials. Additional educational approaches mentioned by the respondents focused primarily on educating women through television and radio, either through advertisements or as the main topic on a talk show. When asked specifically if it would be helpful to have materials that include an English and Vietnamese translation within the same publication, one hundred and thirty respondents (93.5\%) reported yes. 


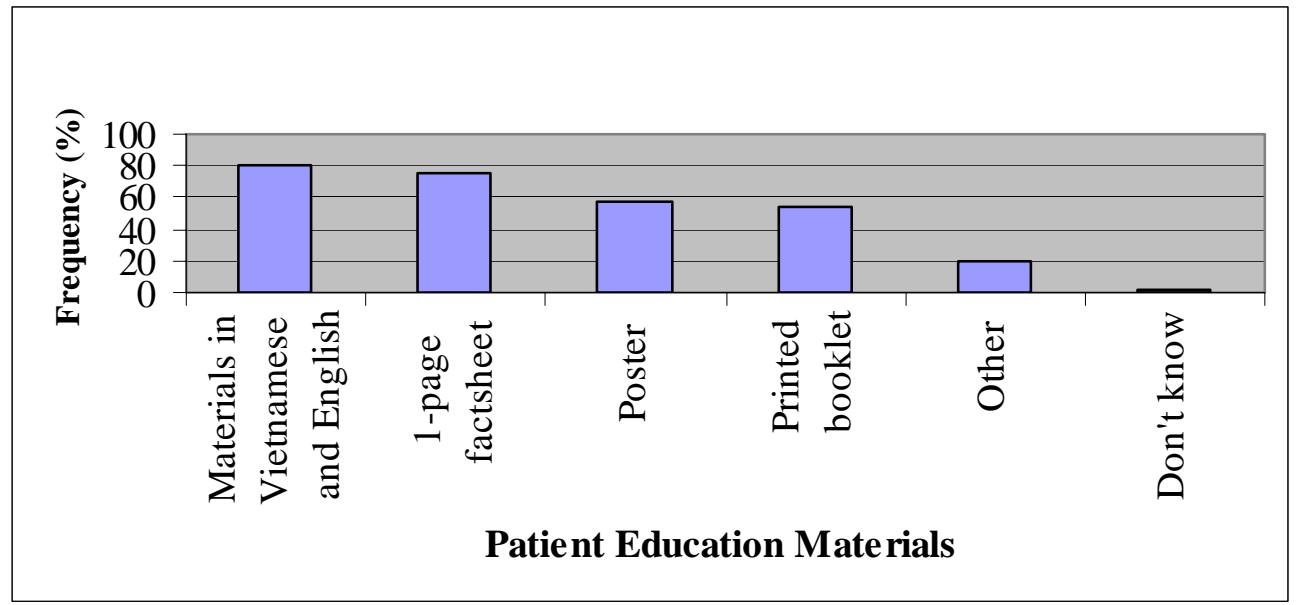

Figure 1

Patient education materials that are preferred by health care providers to help motivate Vietnamese women who have rarely or never received a Pap test $(\mathrm{N}=142)$. Reported as percentage of respondents selecting that patient education material.

\section{Discussion}

This questionnaire provided information from the perspective of providers about barriers to cervical cancer screening among Vietnamese women and contributed suggestions to increase screening in this group. Many of the issues that providers raised as barriers to screening are well documented in the literature (Chilton et al., 2005; McPhee et al., 1997a; Nguyen et al., 2006a; Taylor et al., 2004b). Almost all the respondents (95\%) thought that Pap tests were very important in the early detection of cervical cancer in Vietnamese women living in the United States. However, respondents also thought that a lack of knowledge about the importance of Pap tests was a contributing factor to Vietnamese women not seeking a Pap test. Respondents did not perceive that the cost of a Pap test was a contributing factor to getting a Pap test. This may be because most respondents worked in a private practice setting and assumed that most of their patients have some form of health insurance.

The lack of understanding of the importance of Pap tests with respect to providers and the lack of training to administer Pap tests were seen as significant reasons why Vietnamese providers may not recommend Pap tests. In a previous study on increasing cervical cancer and Pap testing knowledge among Vietnamese American physicians through continuing medical education, Lai and colleagues (2004) found prior to the intervention, many of the Vietnamese American physicians had limited knowledge about cervical cancer screening, were not aware of the cervical cancer risk in Vietnamese women, were not aware of the curability factor if cervical cancer is detected early. In addition, the concept of prevention has not been readily adopted by Vietnamese providers and people (Chilton et al., 2005), which may be a factor in the lack of importance given to cervical cancer screening. Lai et al. (2004) found many Vietnamese physicians do not receive adequate training in prevention and therefore may limit making recommendations for cervical cancer screening. Finally, the fear of losing patients to another provider was a unique finding and to our knowledge, has not been documented in this context.

The need for better patient-provider communication and patient education was indicated among the responses. Vietnamese women who were recommended Pap testing by their physician were almost six times more likely to report having recently participated in screening (Taylor et al., 2004b). In addition, if a Vietnamese female patient had asked her doctor for a Pap test, she was seven times more likely to have reported participation in screening 
(Taylor et al., 2004b). This reinforces the need for providers to engage in patient education about the Pap test and for patients to be proactive in inquiring about cervical cancer screening with their provider.

The relationship between provider gender and screening is also supported in our findings. Our respondents indicated that having a male provider may result in female patients not getting a Pap test even after a recommendation by the provider. Further, respondents indicated that Vietnamese women would prefer female providers. Similar findings were reported by Nguyen et al. (2006a) in that Vietnamese women who had a female Vietnamese physician or a non-Vietnamese physician were more likely to receive screening. Having a male physician, regardless of physician ethnicity, was negatively associated with Pap test screening among Vietnamese women residing in Seattle, Washington (Taylor et al., 2004a). Vietnamese male physicians may be sensitive to their female patients' sense of modesty (Nguyen et al., 2000). Previous research has documented marital status as a predictor of having received a Pap test (Jenkins et al., 1996; Yi, 1998). Some of the reasons why unmarried Vietnamese women may not receive a Pap test may be due to a belief that the Pap test procedure will affect a woman's virginity (Tosomeen et al., 1996; Yi, 1994) or due to the cultural taboos against premarital sex (Rangavajhula \& Hofvendahl-Clark, 2004). Vietnamese providers may be sensitive to these beliefs as well. Unmarried women were less likely to have ever received a Pap test (McPhee et al., 1997a; Nguyen et al., 2006a; Taylor et al., 2004b) which suggests that unmarried women should be especially targeted for cervical cancer screening education.

Our findings related to system barriers experienced by the provider, such as time and cost, are also consistent with the literature (Womeodu \& Bailey, 1996). Our findings on provider perspectives of why Vietnamese women may not get Pap tests even after receiving a provider recommendation correspond to the barriers to Pap test participation reported by Vietnamese women. These findings include lack of knowledge of cervical cancer, being too busy, preference for a female provider, modesty (Nguyen et al., 2006b), and fear (Nguyen et al., 2006b; Schulmeister \& Lifsey, 1999). This indicates that a portion of our respondents are aware of the barriers experienced at the patient level, however, may warrant further continuing medical education to address some of these issues.

Most respondents (93.5\%) indicated that it would be helpful to have materials that include both an English and Vietnamese translation within the same publication. To our knowledge, our findings are the first to document this preference among providers. This important finding points to the need to develop bilingual publications that can enhance doctor-patient communications, and potentially provide increased access to information to Vietnamese American families in which women speak both English and Vietnamese. Additionally, respondents' recommendation to use Vietnamese television, radio, and newspaper as communication channels is corroborated by the finding that exposure to Vietnamese-language media about Pap testing was associated with increased Pap testing (Lam et al., 2003; Nguyen et al., 2006a). Further, a media-led Vietnamese community education campaign on cervical cancer screening consisting of booklets, newspaper advertisements, and television broadcasts, resulted in Vietnamese women getting greater awareness of cervical cancer screening and intention to get a Pap test (Jenkins et al., 1999). Interviews with local health care and community leaders in Houston, Texas, indicated that Vietnamese radio was a primary source of cancer and health information (Chilton et al., 2005).

\section{Limitations of Study}

The authors conducted a targeted needs assessment among members of the Vietnamese American Medical Association to inform the development of a cervical cancer education brochure for Vietnamese women and to expand our cervical cancer education outreach efforts for Vietnamese women. As such, the application of information from this work is limited and may not be generalizable to all Vietnamese 
physicians. First, based on the background of the health care providers, these respondents may not have been appropriate for providing information and recommendations that will help motivate women to get Pap tests; only a small number of respondents $(n=8)$ were in OB/GYN, and only 35.7 percent reported having patients that were mostly female. Further, most respondents received their training in the United States to administer Pap tests, indicating experience with preventive care. Future questionnaires might specifically target Vietnamese health care providers who are in $\mathrm{OB} / \mathrm{GYN}$ or have a large proportion of female patients. Additionally, some of the data may be subject to certain biases including social desirability and subjectivity in analysis of the open-ended responses.

Another limitation was the low response rate (13\%) which may lead to concerns about nonresponse bias. The response rate of 13 percent which was low compared with the average response rate of 61 percent for physician-mailed surveys (Cummings, Savitz, \& Konrad, 2001). However, low response rates are common in mailed physician surveys. In an analysis of physician-mailed survey studies published from 1986 to 1995 involving samples greater than 1,000 physicians, Cummings et al. (2001) found the response rates ranged from 11 percent to 39 percent. In a study of factors associated with response rates in 178 articles published in 1991, physicians were found to have the lowest response rates among all types of respondent groups including dentists, nurses, other health care workers, administrators, patients, students, and other respondents (Asch et al., 1997). Nonresponse bias may not be as significant of a concern in physician surveys in comparison to surveys with non-physicians because physician characteristics (knowledge, attitudes, and behaviors) as a group are more homogeneous than the general population (Kellerman \& Herold, 2001).

\section{Future Research}

Despite these limitations, this formative research has provided feedback from Vietnamese providers about barriers to cervical cancer screening for Vietnamese women living in the United States and educational strategies for increasing screening. Providers underscore the importance of communicating to women the importance of the Pap test and enhancing doctorpatient communications by providing bilingual education materials. Additionally, they confirm findings in the literature that issues of modesty, fear of losing virginity, and pain are important factors for women. Finally, findings influencing Vietnamese provider recommendations pointed to the importance of increasing provider awareness of high risk among Vietnamese women, addressing barriers of modesty that women may experience, and gender of the physician. Many of our findings have been confirmed by findings from previous research.

On the basis of the information provided by the respondents, future educational materials to motivate Vietnamese women to receive routine Pap tests may well serve this population by raising awareness of the importance of Pap tests among Vietnamese women and addressing system barriers, such as access to screening services, and language and cultural barriers, including modesty and fear. Health communication plans should include using print materials containing both English and Vietnamese text and simple and concise information (e.g., one-page fact sheets). In addition, Vietnamese television, radio, and newspapers should be used to educate Vietnamese women on the importance of cervical cancer screening. Health care providers are a critical source for communication of the importance of cancer screening. For providers serving Vietnamese women, continuing medical education is needed to address the awareness of the cervical cancer burden in the Vietnamese population and make cervical cancer screening recommendations.

The National Cancer Institute has applied much of this information to the development of our cervical cancer education materials for Vietnamese women and providers living in the United States. It is hoped that this work will encourage others to develop materials and programs to address these barriers to cervical cancer screening, as well as continue to explore root causes of lack of screening among Vietnamese women living in the United States. 


\section{References}

Asch, D. A., Jedrziewski, M. K., \& Christakis, N. A. (1997). Response rates to mail surveys published in medical journals. Journal of Clinical Epidemiology, 50, 1129-1136.

Chilton, J. A., Gor, B. J., Hajek, R. A., \& Jones, L. A. (2005). Cervical cancer among Vietnamese women: Efforts to define the problem among Houston’s population. Gynecologic Oncology, 99, S203-S206.

Cummings, S. M., Savitz, L. A., \& Konrad, T. R. (2001). Reported response rates to mailed physician questionnaires. Health Services Research, 35, 1347-1355.

De Alba, I., Ngo-Metzger, Q., Sweningson, J. M., \& Hubbell, A. (2005). Pap smear use in California: Are we closing the racial/ethnic gap? Preventive Medicine, 40, 747-755.

Hyman, I., Cameron, J. I., Singh, P. M., \& Stewart, D. E. (2003). Physicians and Pap testing in the Chinese and Vietnamese communities in Toronto. Journal of Health Care for the Poor and Underserved, 14, 489-502.

Jenkins, C. N. H., McPhee, S. J., Bird, J. A., Pham, G. Q., Nguyen, B. H., Nguyen, T. et al. (1999). Effect of a media-led education campaign on breast and cervical cancer screening among VietnameseAmerican women. Preventive Medicine, 28, 395-406.

Jenkins, C. N. H., Le, T., McPhee, S. J., Stewart, S., \& Ha, N. T. (1996). Health care access and preventive care among Vietnamese immigrants: Do traditional beliefs and practices pose barriers? Social Science \& Medicine, 43, 1049-1056.

Kellerman, S. E., \& Herold, J. (2001). Physician response to surveys. A review of the literature. American Journal of Preventive Medicine, 20, 61-67.

Lai, K. Q., Nguyen, T. T., Mock, J., McPhee, S. J., Doan, H. T., \& Pham, T. H. (2004). Increasing Vietnamese-American physicians' knowledge of cervical cancer and Pap testing: Impact of continuing medical education programs. Ethnicity \& Disease, 14(3 Suppl. 1), S1-122, 127.

Lam, T. K., McPhee, S. J., Mock, J., Wong, C., Doan, H. T., Nguyen, T. et al. (2003). Encouraging Vietnamese-American women to obtain Pap tests through lay health worker outreach and media education. Journal of General Internal Medicine, 18, 516-524.

McPhee, S. J. (2002). Caring for a 70-year-old Vietnamese woman. Journal of the American Medical Association, 287, 495-504.

McPhee, S. J., Stewart, S., Brock, K. C., Bird, J. A., Jenkins, C. N., \& Pham, G. Q. (1997a). Factors associated with breast and cervical cancer screening practices among Vietnamese American women. Cancer Detection and Prevention, 21, 510-521.

McPhee, S. J., Bird, J. A., Davis, T., Ha, N-T., Jenkins, C. N., \& Le, B. (1997b). Barriers to breast and cervical cancer screening among Vietnamese-American women. American Journal of Preventive Medicine, 13, 205-213.

National Cancer Institute. (1996). Racial/ethnic patterns of cancer in the United States, 1988-1992. Bethesda, MD: National Institutes of Health.

National Institutes of Health. (1996). NIH Consensus Statement Online, 43(1), 1-38.

Nguyen, T. T., McPhee, S. J., Gildengorin, G., Nguyen, T., Wong, C., Lai, K. Q. et al. (2006a). Papanicolau testing among Vietnamese Americans - Results of a multifaceted intervention. American Journal of Preventive Medicine, 31, 1-9.

Nguyen, T. T., McPhee, S. J., Bui-Tong, N., Luong, T. N., Ha-Iaconis, T., Nguyen, T., Wong, C., Lai, K. Q., \& Lam, H. (2006b). Community-based participatory research increases cervical cancer screening among Vietnamese-Americans. Journal of Health Care for the Poor and Underserved, 17, 31-54.

Nguyen, T. T., McPhee, S. J., Nguyen, T., Lam, T., \& Mock, J. (2002). Predictors of cervical Pap smear screening awareness, intention, and receipt among Vietnamese-American women. American Journal of Preventive Medicine, 23, 207-214.

Nguyen, B. H., Nguyen, K. P., McPhee, S. J., Nguyen, A. T., Tran, D. Q., Jenkins, C. N. H. (2000). Promoting cancer prevention activities among Vietnamese physicians in California. Journal of Cancer Education, 15, 82-85. 
Rangavajhula, R., \& Hofvendahl-Clark, K. (2004). Vietnamese-American women and cervical cancer screening: A missed opportunity? Californian Journal of Health Promotion, 2(1), 120-126.

Schulmeister, L., \& Lifsey, D. S. (1999). Cervical cancer screening knowledge, behaviors, and beliefs of Vietnamese women. Oncology Nursing Forum, 26, 879-887.

Swan, J., Breen, N., Coates, R. J., Rimer, B. K., \& Lee, N. C. (2003). Progress in cancer screening practices in the United States: Results from the 2000 National Health Interview Survey. Cancer, 97, 1528-1540.

Taylor, V. M., Schwartz, S. M., Yasui, Y., Burke, N., Shu, J., Lam, D. H. et al. (2004a). Pap testing among Vietnamese women: Health care system and physician factors. Journal of Community Health, 29, 437-450.

Taylor, V. M., Yasui, Y., Burke, N., Nguyen, T., Acorda, E., Thai, H. et al. (2004b). Pap testing adherence among Vietnamese American women. Cancer Epidemiology, Biomarkers \& Prevention, 13, 613-619.

Tosomeen, A. H., Marquez, M. A., Panser, L. A., \& Kottke, T. E. (1996). Developing preventive health programs for recent immigrants. A case study of cancer screening for Vietnamese women in Olmsted County, Minnesota. Minnesota Medicine, 79(5), 46-48.

Womeodu, R. J., \& Bailey, J. E. (1996). Barriers to cancer screening. Medical Clinics of North America, 80, 115-133.

Yi, J. K. (1994). Factors associated with cervical cancer screening behavior among Vietnamese women. Journal of Community Health, 19, 189-200.

Yi, J. K. (1998). Acculturation and Pap smear screening practices among college-aged Vietnamese women in the United States. Cancer Nursing, 21, 335-341.

\title{
Acknowledgements
}

The authors would like to thank the Vietnamese American Medical Association and ORC Macro for their contributions to this needs assessment study. We would also like to thank Lenora Johnson, Director of the Office of Education and Special Initiatives, and Anita Ousley, Acting Chief of the Professional Education \& Research Dissemination Branch in the Office of Education and Special Initiatives, for reviewing this manuscript.

\author{
Author Information \\ Harry T. Kwon, M.P.H., CHES* \\ Public Health Educator \\ Office of Education and Special Initiatives \\ National Cancer Institute \\ 6116 Executive Blvd. Suite 202 \\ Bethesda, MD 20892-8334 \\ Ph.: 301-451-4210 \\ Fax.: 301-496-7063 \\ Email: Kwonh@mail.nih.gov \\ Felicia M. Solomon, M.P.H. \\ Public Health Advisor \\ Office of Education and Special Initiatives \\ National Cancer Institute \\ Si Nguyen, M.D. \\ Vietnamese American Medical Association \\ * corresponding author
}

